\title{
Comparative analysis of results from experimental and numerical studies on concrete strength
}

\author{
Oleg Mkrtychev ${ }^{1}$, Dmitriy Sidorov ${ }^{1}$ and Sergey Bulushev ${ }^{1 *}$ \\ ${ }^{1}$ Moscow state university of civil engineering, Yaroslavskoye shosse, 26, Moscow, Russia, 129337
}

\begin{abstract}
Some results of numerical experiments of testing concrete cubes and prisms on unconfined compression, and the comparison of results obtained with experimental and specified data, are presented in the article. When performing calculations of structures in a nonlinear setting, it is very important to choose adequate deformation diagrams or material models. Because of the fact that there are no instructions how to use the diagrams of concrete and armature deformation in collaboration of steel and concrete, the simulation of reinforced concrete structures by finite elements of the same type without any assumptions is impossible. Numerical experiments have been performed in the LS-DYNA software package. This software package allows simulating the collaboration of concrete and steeling with the help of three-dimensional (for concrete) and rod (for the reinforcement) finite elements. As samples, a cube and a prism with dimensions of 150x150x150 mm and 150x150x600 mm, respectively, have been taken. The samples are simulated by solid finite elements. For the simulation of concrete, the non-linear CSCM (Continuous Surface Cap Model) material is used. The tests were carried out with samples of the following classes of concrete as for cylinder compressive strength: $\mathrm{C} 12$, $\mathrm{C} 16, \mathrm{C} 20, \mathrm{C} 25, \mathrm{C} 30, \mathrm{C} 35$. This corresponds to the following classes of cube compression strength: B15, B20, B25, B30, B37, B45. The tests have been carried out considering the friction coefficients between the plates of a testing machine, and a sample. The performed researches have shown that the destruction nature of the samples in a numerical experiment corresponds to the failure nature in real tests. The investigated model of CSCM concrete can be used in the calculation of concrete and reinforced concrete structures with acceptable accuracy for main classes of concrete.
\end{abstract}

\section{Introduction}

When performing calculations of structures in a nonlinear setting, it is very important to choose adequate deformation diagrams or material models. The behaviour of steel structures can be precisely and simply modeled by finite elements using the diagrams described in [1]. The diagrams of deformation of concrete and reinforcement are given in [2]. However, there are no instructions how to use these diagrams in collaboration of steel

\footnotetext{
*Corresponding author: sergey.bulushev@gmail.com
} 
and concrete. Thus, the simulation of reinforced concrete structures by finite elements of the same type without any assumptions is impossible. Modern software packages, such as LS-DYNA, ANSYS, and others, allow simulating the collaboration of concrete and steel with the use of solid (for concrete) and rod (for reinforcement) finite elements. In this setting, for rod-like finite elements, we can use the diagrams presented in [2]. The behaviour of concrete in the case of triaxial stress state cannot be fully described by a concrete deformation diagram obtained under uniaxial compression. It is necessary to use more complex models of concrete.

\section{Research Objective}

The purpose of this study is to perform numerical experiments to test concrete cubes and prisms on uniaxial compression and compare the results with experimental and normative data.

Numerical experiments are implemented in the LS-DYNA software package.

As samples, in accordance with [3], a cube and a prism with dimensions of 150x150x150 mm and 150x150x600 mm, respectively, were taken. The samples are modeled by solid finite elements. The lower and upper plates of the testing machine are also made of solid finite elements (Figure 1). The lower plate is fixed to avoid all possible displacements, the upper one can move only in vertical direction.
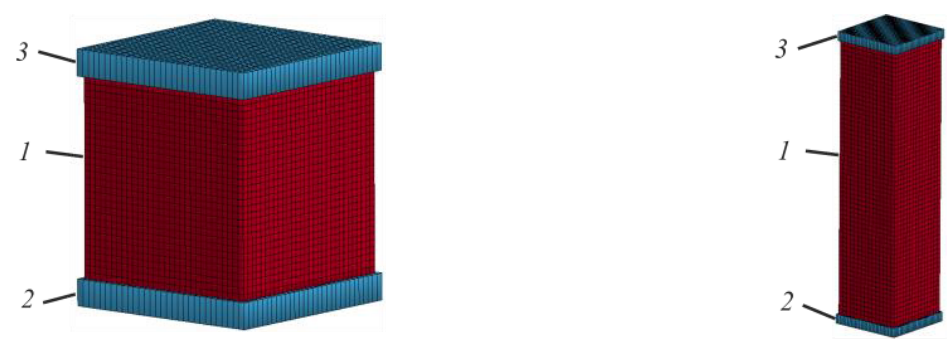

Fig. 1. Testing model. 1 - test sample, 2 - lower support plate of a testing machine, 3 - upper support plate of a testing machine (press).

Material of plates is steel. For the simulation of concrete, CSCM non-linear material [47] is used.

In the course of the experiment, a gradually increasing load is applied to the upper plate, and the sample is brought to destruction.

The tests were performed with samples of the following classes of concrete as for cylinder compressive strength: C12, C16, C20, C25, C30, C35 [8-10]. This corresponds to the following classes of cube compression strength: B15, B20, B25, B30, B37, B45 [8-10].

The tests were also carried out with different friction coefficients between the plates of the test machine and the sample.

\section{Results of Investigations}

The researches carried out have shown that the destruction nature of the samples in a numerical experiment corresponds to the nature of failure in real tests. The destruction of the cube with allowance for friction is shown in Figure 2. 

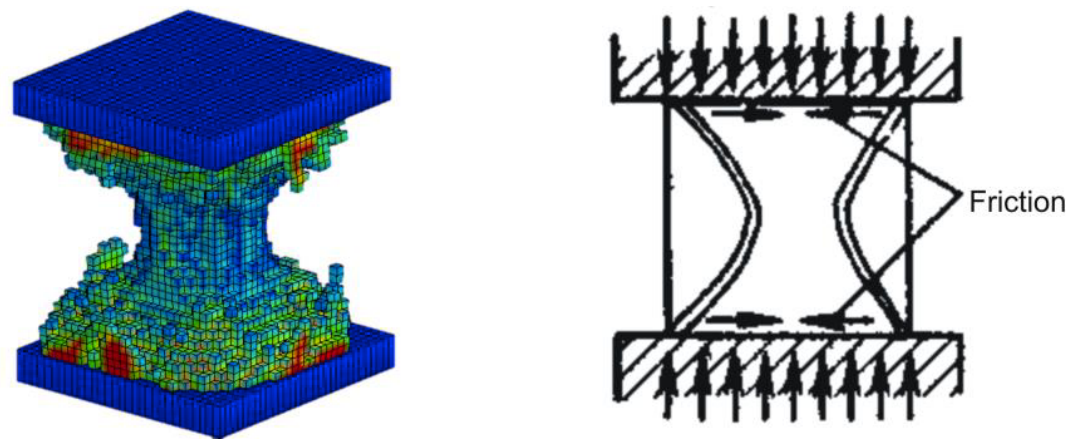

Fig. 2. Pattern of the concrete cube destruction with allowance for friction. Numerical experiment (left), experimental data (right).

When the friction decreases, the pattern of destruction changes (Figure 3). And herewith, the strength of the cube is reduced by 1.5-2 times. For a prism with specified dimensions, the friction variation hardly affects. These results also correspond to the experimental data [11]. The pattern of the destruction of the prism is shown in Fig 4.
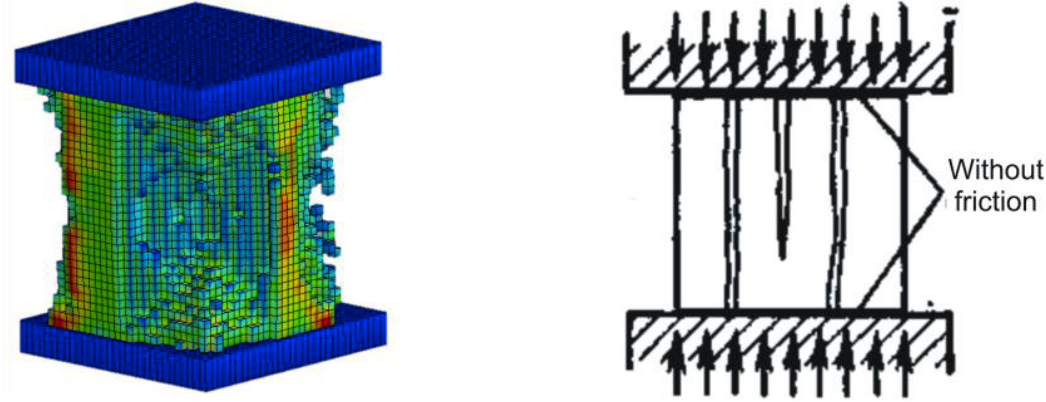

Fig. 3. Pattern of the destruction of the concrete cube without considering the friction. Numerical experiment (left), experimental data (right).
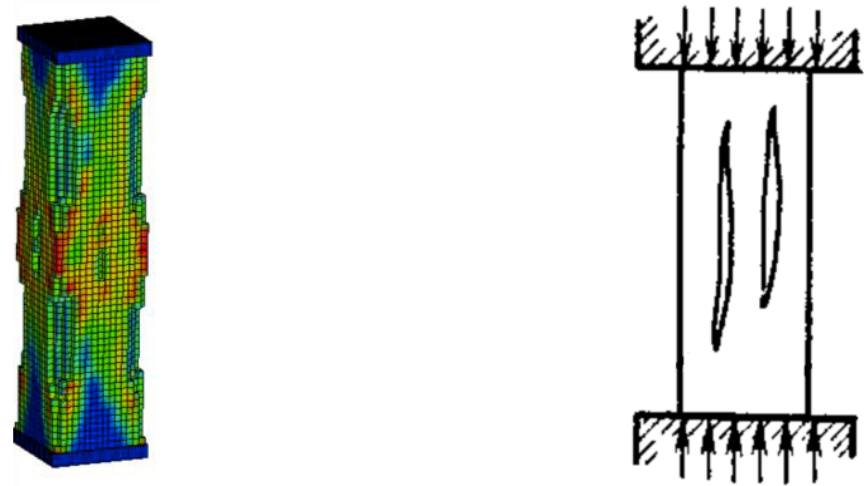

Fig. 4. Pattern of the destruction of the concrete prism without considering the friction. Numerical experiment (left), experimental data (right).

In the course of numerical experiments, the values of the destructive load for cubes and prisms were recorded with allowance for friction. These values correspond to the average cube strength and average prismatic strength. The data obtained were compared with the normative values. The results for different classes of concrete are given in Tables 1-6. 
Table 1. Concrete B15.

\begin{tabular}{|c|c|c|c|}
\hline \multirow{2}{*}{ Characteristics } & \multicolumn{3}{|c|}{ Concrete B15 (C12) } \\
\cline { 2 - 4 } & Specified value & $\begin{array}{c}\text { Numerical } \\
\text { experiment }\end{array}$ & $\Delta$ \\
\hline$f_{\text {cm }}($ mean cyl.) $\mathrm{MPa}$ & 20 & - & - \\
\hline$f_{\text {cm, cube }}($ mean cube) $\mathrm{MPa}$ & 19.3 & 22.5 & $16.58 \%$ \\
\hline$f_{\text {cm,prism }}($ mean prism) $\mathrm{MPa}$ & 14.5 & 15.3 & $5.52 \%$ \\
\hline
\end{tabular}

Table 2. Concrete B20.

\begin{tabular}{|c|c|c|c|}
\hline \multirow{2}{*}{ Characteristics } & \multicolumn{3}{|c|}{ Concrete B20 (C16) } \\
\cline { 2 - 4 } & Specified value & $\begin{array}{c}\text { Numerical } \\
\text { experiment }\end{array}$ & $\Delta$ \\
\hline$f_{\text {cm }}$ (mean cyl.) MPa & 24 & - & - \\
\hline$f_{\text {cm,cube }}$ (mean cube) MPa & 25.7 & 26.1 & $1.56 \%$ \\
\hline$f_{\text {cm,prism }}($ mean prism) $\mathrm{MPa}$ & 19.3 & 20.3 & $5.18 \%$ \\
\hline
\end{tabular}

Table 3. Concrete B25.

\begin{tabular}{|c|c|c|c|}
\hline \multirow{2}{*}{ Characteristics } & \multicolumn{3}{|c|}{ Concrete B25 (C20) } \\
\cline { 2 - 4 } & Specified value & $\begin{array}{c}\text { Numerical } \\
\text { experiment }\end{array}$ & $\Delta$ \\
\hline$f_{\mathrm{cm}}($ mean cyl.) MPa & 28 & - & - \\
\hline$f_{\mathrm{cm}, \text { cube }}($ mean cube) $\mathrm{MPa}$ & 32.1 & 30.9 & $-3.74 \%$ \\
\hline$f_{\mathrm{cm}, \text { prism }}($ mean prism) $\mathrm{MPa}$ & 24.1 & 25.5 & $5.81 \%$ \\
\hline
\end{tabular}

Table 4. Concrete B30.

\begin{tabular}{|c|c|c|c|}
\hline \multirow{2}{*}{ Characteristics } & \multicolumn{3}{|c|}{ Concrete B30 (C25) } \\
\cline { 2 - 4 } & Specified value & $\begin{array}{c}\text { Numerical } \\
\text { experiment }\end{array}$ & $\boldsymbol{\Delta}$ \\
\hline$f_{\mathrm{cm}}($ mean cyl.) $\mathrm{MPa}$ & 33 & - & - \\
\hline$f_{\mathrm{cm}, \text { cube }}($ mean cube) $\mathrm{MPa}$ & 38.5 & 35.1 & $-8.83 \%$ \\
\hline$f_{\mathrm{cm}, \text { prism }}($ mean prism) $\mathrm{MPa}$ & 28.9 & 30.3 & $4.84 \%$ \\
\hline
\end{tabular}

Table 5. Concrete B37.

\begin{tabular}{|c|c|c|c|}
\hline \multirow{2}{*}{ Characteristics } & \multicolumn{3}{|c|}{ Concrete B37 (C30) } \\
\cline { 2 - 4 } & Specified value & $\begin{array}{c}\text { Numerical } \\
\text { experiment }\end{array}$ & $\boldsymbol{\Delta}$ \\
\hline$f_{\mathrm{cm}}($ mean cyl.) MPa & 38 & - & - \\
\hline$f_{\mathrm{cm}, \text { cube }}($ mean cube) $\mathrm{MPa}$ & 47.5 & 39.0 & $-17.89 \%$ \\
\hline$f_{\mathrm{cm}, \text { prism }}($ mean prism) $\mathrm{MPa}$ & 35.6 & 33.9 & $-4.78 \%$ \\
\hline
\end{tabular}

Table 6. Concrete B45.

\begin{tabular}{|c|c|c|c|}
\hline \multirow{2}{*}{ Characteristics } & \multicolumn{3}{|c|}{ Concrete B45 (C35) } \\
\cline { 2 - 4 } & Specified value & $\begin{array}{c}\text { Numerical } \\
\text { experiment }\end{array}$ & $\Delta$ \\
\hline$f_{\text {cm }}$ (mean cyl.) $\mathrm{MPa}$ & 43 & - & - \\
\hline$f_{\text {cm,cube }}($ mean cube) $\mathrm{MPa}$ & 57.8 & 42.5 & $-26.47 \%$ \\
\hline$f_{\mathrm{cm}, \text { prism }}($ mean prism) $\mathrm{MPa}$ & 43.4 & 37.9 & $-12.67 \%$ \\
\hline
\end{tabular}

The specified values of the average cube strength are taken from [10]. The average prismatic strength is accepted as $75 \%$ of the cube [9].

In Figures 5 and 6, the results obtained are presented in the form of graphs. 


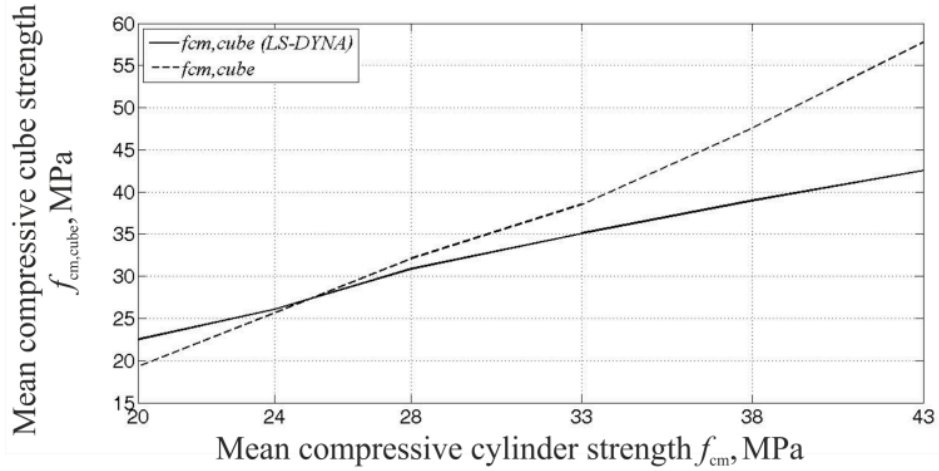

Fig. 5. Average cube strength depending upon the average cylinder strength.

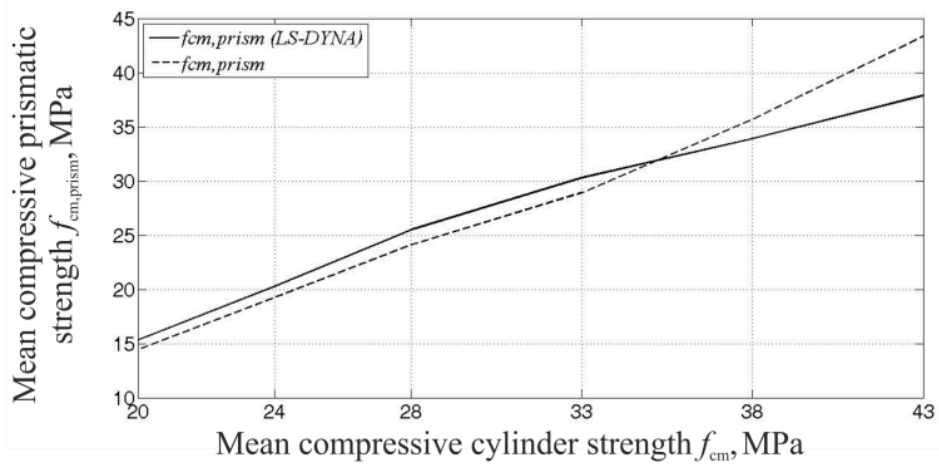

Fig. 6. Average prismatic strength depending upon the average cylinder strength.

\section{Conclusions}

The conducted researches showed:

1. The character of destruction of concrete cubes and prisms obtained in numerical studies corresponds to experimental data.

2. The divergence of cube strength for concrete classes B20-B30 is not more than $9 \%$ in comparison with the standard (experimental) values.

3. The obtained values of the average prismatic strength for all concrete classes studied, with the exception of concrete B45, show good convergence with normative values. The discrepancies are not more than $6 \%$.

Thus, it can be concluded that the investigated CSCM concrete model can be used in the calculation of concrete and reinforced concrete structures with acceptable accuracy for the main classes of concrete used in mass construction. For concretes of class more than B35, additional studies are necessary.

\section{Acknowledgements}

This study was performed with the financial support of the RF Ministry of Education and Science, grant \#7.1524.2017/Project Part. 


\section{References}

1. Proprietary standard ADSC 11251254.001-2015 «Composite structures. Design rules» (Association of Business Development Associates for the Development of Steel Construction, Moscow, 2015)

2. SP 63.13330.2012 Concrete and Reinforced Concrete Structures. Summary (2012)

3. State standard 10180-2012 Concrete. Methods for determining the strength of control samples (2012)

4. US Department of Transportation. Federal Highway Administration. Evaluation of LSDYNA Concrete. Material Model 159. FHWA-HRT-05-063, 190 (2007)

5. Y.D. Murray, Users Manual for LS-DYNA Concrete Material Model 159, FHWAHRT-05-062 (2007)

6. O. V. Mkrtychev, M. S. Busalova, Proc.Eng., 153, 475 (2016)

7. O. V. Mkrtychev, M. S. Busalova, Adv. in Eng, Res., 104, 160 (2016)

8. EN 1992-1-1 Eurocode 2: Design of concrete structures - Part 1-1 : General rules and rules for buildings (2004)

9. T. Telford Designers' guides to the Eurocodes. Designers' guides to Eurocode 2: Design of concrete structures designers' guide to EN1992-1-1 and EN1992-1-2 Eurocode 2 : Design of concrete structures general rules and rules for buildings and structural fire design (2005)

10. T. Telford Comite Euro-Internetional du beton CEB-FIP model code 1990. Design code (1993)

11. V. N. Baikov, E. E. Sigalov Reinforced concrete structures. General course (Stroyizdat, Moscow, 1984)

12. Heavy and fine-grained concretes. Specifications. State standard 26633-91 (State Construction Committee of the USSR, Moscow, 1991) 